\title{
Mutations which Affect Amino Acid Transport in Aspergillus nidulans
}

\author{
By J. R. KINGHORN AND J. A. PATEMAN \\ Department of Genetics, University of Glasgow, Glasgow GI I $5 J S$
}

(Received 9 July 1974; revised 22 August 1974)

\begin{abstract}
SUMMAR Y
Mutants deficient in amino acid transport ( $a a u$ ), and unable to utilize L-glutamate as a sole carbon and nitrogen source, have been isolated. There are four unlinked genes involved: $a a u A, a a u B, a a u C$ and $a a u D$. The transport levels of certain amino acids, and the growth characteristics on certain nitrogen and carbon sources and toxic amino acid analogues, indicate that: aau $A I$ has defective transport of acidic amino acids; $a a u B r$ has defective transport of acidic and neutral amino acids; $a a u C I$ and $a a u D I$ have defective transport of acid, neutral and aromatic amino acids. $a a u A I$ and $a a u B I$ are recessive for all three characteristics in the heterozygous diploid; $a a u C I$ and $a a u D I$ are dominant.
\end{abstract}

\section{INTRODUCTION}

In the fungi, a number of specific transport systems for amino acids and related substances have been described. These include ammonium (Pateman, Kinghorn, Dunn \& Forbes, 1973; Pateman, Dunn, Kinghorn \& Forbes, 1974) and urea (Dunn \& Pateman, 1972) in Aspergillus nidulans, arginine, lysine, methionine and histidine in Saccharomyces cerevisiae (Grenson, I966; Grenson, Mousset, Wiame \& Béchet, I966; Gits \& Grenson, 1967; Crabeel \& Grenson, 1970), and ammonium, methionine, cysteine, proline, lysine and arginine, as well as distinct acidic and basic systems, in Penicillium chrysogenum (Benko, Wood \& Segel, 1967; Hackette, Skye, Burton \& Segel, 1970; Skye \& Segel, 1970; Hunter \& Segel, 197I). Moreover, the isolation of mutants defective in the transport of specific amino acids is strong evidence for the existence of specific uptake systems. However, general amino acid transport systems have also been described in the fungi. The presence of a 'general' amino acid system has been reported for Botrytis fabae (Jones, 1963), Arthrobotrys conoides (Gupta \& Pramer, 1970), S. cerevisiae (Grenson, Hou \& Crabeel, 1970; Grenson \& Hou, I972), Neurospora crassa (Pall, 1969), and P. chrysogenum (Benko, Wood \& Segel, I969). Mutants have been isolated which have simultaneously lost the ability to transport a number of amino acids, e.g. gap and apf in yeast (Surdin et al. 1965; Grenson et al. 1970; Grenson \& Hennaut, I97I), un-t, nap and $m t r$ in $N$. crassa (Kappy \& Metzenberg, 1965; Stadler, I966; Lester, I966; Jacobson \& Metzenberg, 1968) and fpaD in A. nidulans (Sinha, 1969).

We describe the isolation and properties of new classes of mutants mapping at four loci in A. nidulans which are defective in the transport of a number of amino acids. A preliminary report of this work was given at a meeting of the Genetical Society of Great Britain (Kinghorn \& Pateman, 1972).

\section{METHODS}

Chemicals. Analytical grade chemicals were used whenever possible: ${ }^{14} \mathrm{C}$-labelled L-amino acids, $\left[{ }^{14} \mathrm{C}\right]$ methylammonium and thio $\left[{ }^{14} \mathrm{C}\right]$ urea were obtained from The Radiochemical Centre, Amersham, Buckinghamshire. 
Strains. A biotin- and putrescine-requiring strain, biI puA2 (Glasgow No. OI7I), was used as the prototroph with respect to nitrogen metabolism.

Media. Medium used for genetic analysis was essentially that described by Pontecorvo et al. (1953). Nitrogen-less minimal medium ( $-\mathrm{N}$ medium) described by Cove (I966), and carbon- and nitrogen-less minimal medium ( $-\mathrm{CN}$ medium) were used. Most nitrogen and carbon sources used in media were kept as sterile stock solutions at I M. Others such as urea, L-asparagine and L-glutamine, which are unstable with ammonium as one of the products, were made up immediately before use.

Growth tests of mutants were carried out in Petri dishes containing $20 \mathrm{ml}-\mathrm{N}$ or $-\mathrm{CN}$ medium (solid) plus the nitrogen or carbon source under test. These were carefully pointinoculated with fresh conidia and incubated at $37^{\circ} \mathrm{C}$ for approximately 30 to $36 \mathrm{~h}$. Growth, in terms of colony size and density, was recorded as,+++ or - .

Selection of transport mutants. The putrescine technique of Herman \& Clutterbuck (I 966) was used to isolate mutants unable to utilize L-glutamate as a sole carbon and nitrogen source. $N$-methyl- $N^{\prime}$-nitro- $N$-nitrosoguanidine treated conidia (Adelberg, Mandel \& Chen, 1965) of biI puAz were point-inoculated on to $-\mathrm{CN}$ medium plus limiting putrescine $\left(9.7 \times 10^{-7} \mathrm{M}\right)$ plus $100 \mathrm{mM} \mathrm{L}$-glutamate. After 3 to 4 days' incubation at $37^{\circ} \mathrm{C}$, sectors showing spidery growth were isolated and purified.

Genetic analysis. The genetic techniques were those described by Pontecorvo et al. (1953) and McCully \& Forbes (1965), with the exception that acridine yellow $(0.06 \mathrm{mg} / \mathrm{ml})$ was used as the haploidization agent instead of $p$-fluorophenylalanine.

Growth of mycelium for uptake assays. The uptake of ${ }^{14} \mathrm{C}$-labelled amino acids was determined during exponential growth phase in an attempt to study transport in young cells under as standard and reproducible conditions as possible. Mycelium was grown in culture shaken at $200 \mathrm{rev} . / \mathrm{min}$ (rotary motion describing a $\mathrm{I}$ in circle) in a controlled environment incubator shaker (Psycrotherm; New Brunswick Scientific Co., New Brunswick, New Jersey, U.S.A.) for approximately 18 to $20 \mathrm{~h}$ at $25^{\circ} \mathrm{C}$, and harvested by filtering on nylon cloth (Cove, 1966). When mycelium was given some special treatment, it was transferred after harvesting to the preheated treatment medium for the appropriate time and then reharvested. The mycelium was pressed dry with paper towels and weighed. Yields were usually 5 to $8 \mathrm{~g} / \mathrm{l}$ medium. Cells were used immediately for uptake assays.

Amino acid transport assay. The method is basically that described in previous communications (Kinghorn \& Pateman, 1973, 1974a). The growth and treatment media are described in the text. The final concentration $(\mu \mathrm{M})$ and specific activity $(\mathrm{mCi} / \mathrm{mmol}$, in parentheses) of each amino acid used were as follows: L-alanine, I00 (I69); L-arginine, IOO (42); L-glutamate, I00 (23I); L-glutamine, 200 (42); L-phenylalanine, 200 (4); L-serine, I00 (I62); methylammonium, 500 (54); thiourea, 200 (I8.3). The final approximate specific activities of each amino acid were as follows $(\mu \mathrm{Ci})$ : L-alanine, $6 \cdot 0$; L-arginine, I.5; L-glutamate, 0.5 ; L-glutamine, 3.5 ; L-phenylalanine, 2.0 ; L-serine, 9; methylammonium, 2.5 ; thiourea, 2.5 . The amino acids were uniformly labelled.

\section{RESULTS}

\section{Isolation of mutants}

A large number of mutants unable to grow on L-glutamate as a sole carbon and nitrogen source were isolated (Kinghorn \& Pateman, 1973, 1974b). Six of these mutants possessed low levels of L-glutamate transport. 
(a) $a$ alu

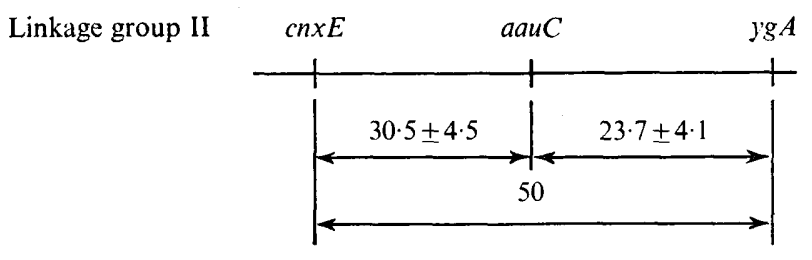

(b) $a a u B$

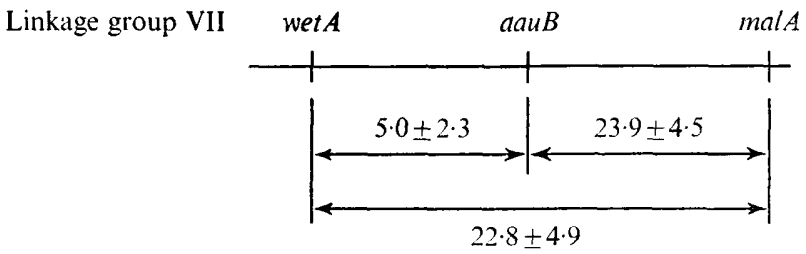

Fig. I. Linkage relationships of $a a u B$ and $a a u C$ to established markers, given as the mean percentage recombination \pm S.E.M. An explanation of symbols and a complete linkage map are given by Clutterbuck (1974). The data in (b) do not exclude the possibility that $a a u B$ is located to the left of wet $A$.

\section{Genetic analysis}

Mitotic and meiotic genetic analysis, as discussed below, showed that four gene loci were involved. These loci were designated aauA (amino acid uptake), aauB, aauC and aauD.

aauA locus. Haploidization of the diploid between bir; puA2; aauAI and master strain D by the method of McCully \& Forbes (1965) yielded segregants which showed free assortment between aauAI and all chromosome markers except nicB. Analysis of a single mixed perithecium from the cross: bir; puA2; aauAI by $y A 2$; palD nicB malA wet $A$ failed to locate aauAI, since aauAI showed approximately $50 \%$ recombination with palD, nicB, malA and wet $A$ (available markers in linkage group VII) amongst I6I progeny tested. Therefore the position of aauAI in linkage group VII is not known.

$a a u B$ locus. Haploidization analysis showed that a further two mutants were located in linkage group VII. The mutations were allelic, or closely linked, since no wild-type recombinant progeny were isolated in a total of 500 progeny scored. The locus was designated $a a u B$ and the mutations $a a u B I$ and $a a u B 2$. Crosses between bir; puA2; aauBI and $y A I$; pyro $A 4$; aau $A T$ gave approximately $50 \%$ recombination for the two genes (280 progeny tested). Crosses between bir; puA2; aauBI or bir; puAz; aauBz and $y A 2$; palD nicB malA wet $A$ located the $a a u B$ locus near wet $A$ (Fig. I).

aauC locus. Haploidization analysis of the diploids between bir; puAz; aauCI or bir; $p u A 2$; aauC2 and the tester strain $\mathrm{D}$ was carried out with complete medium plus acridine yellow $(0.06 \mathrm{mg} / \mathrm{ml})$. Acridine yellow was used instead of $p$-fluorophenylalanine since the $a a u C I$ and $a a u C 2$ mutations are dominant and resistant to $p$-fluorophenylalanine. Both mutant characteristics assorted freely with all chromosome markers except $a c r A$, and consequently were assigned to linkage group II. The results of crosses between bir, puA2, aauCI and $y A 2$, pyroA4, aauC2 showed they were allelic or closely linked; no wild-type recombinants were isolated in 450 progeny. The results of crosses between bir, puA2, aauCI or bir, $p u A 2$, aauC2 and acrA wA thiA abA cnxE ygA located the aauC locus in the $c n x E-y g A$ interval in linkage group II (Fig. I).

aauD locus. As before, acridine yellow was used as the haploidization agent. aauDI assorted freely with all chromosome markers except $r i b o B$ and was therefore assigned to 


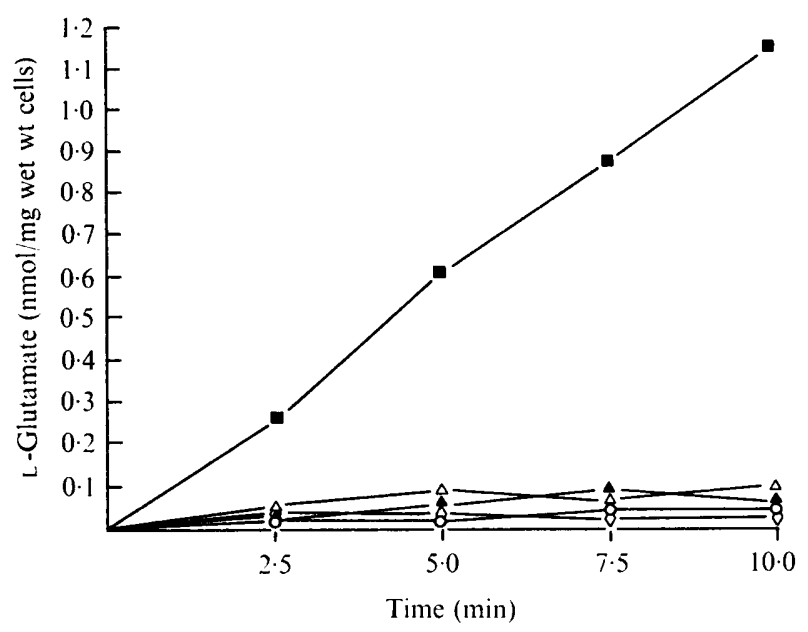

Fig. 2. L-Glutamate transport by wild-type and aau mutants. The cells were grown on $-\mathbf{N}$ medium +

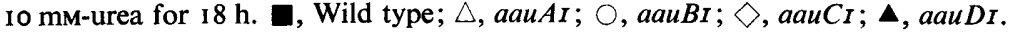

linkage group VIII. A cross between $a a u D_{I}$ and $f p a D_{43}$, which is also an amino acid transport mutant and maps in this linkage group (Sinha, I969), showed that aauDI and $f_{p a D} 43$ are not allelic but loosely linked (approximately $20 \%$ recombination in 410 progeny tested).

\section{Transport of amino acid by wild-type and aau mutants}

The following amino acids and inorganic nitrogen compounds were used to determine the transport characteristics of aau mutants: L-glutamate (acidic), L-phenylalanine (aromatic), L-alanine and L-serine (neutral), L-arginine and L-glutamine (basic), thiourea and methylammonium (inorganic). From the data in Fig. 2, it can be seen that all classes of uptake mutants had low uptake of L-glutamate ( $<10 \%$ of the wild type). The heterozygous diploids $a a u A I / a a u A^{+}$and $a a u B I / a a u B^{+}$appeared to have wild-type transport while aauCI/ $a a u C^{+}$and $a a u D I / a a u D^{+}$showed the mutant level, indicating that aauAr and aauBI mutants are recessive to their wild-type alleles while $a a u C_{I}$ and $a a u D_{I}$ are dominant (Fig. 3). The mutants $a a u B I, a a u C I$ and $a a u D_{I}$, but not $a a u A I$, had impaired transport of the neutral amino acids L-serine (Fig. 4) and L-alanine (Fig. 5), while only aauCI and aauDI had impaired uptake of the aromatic representative L-phenylalanine (Fig. 6). All genotypes had normal uptake of the basic amino acids L-arginine and L-glutamine, and also normal uptake of thiourea and methylammonium.

In summary, aauAI shows low uptake of only acidic amino acids and is recessive. $a a u B I$ shows low uptake of acidic and neutral amino acids and is recessive. aauCI and aauDI have low uptake of acidic, neutral and aromatic amino acids, and in contrast to aauAI and $a a u B I$, are dominant.

\section{Growth responses of aau mutants}

Table I shows the growth characteristics of the four classes of uptake mutants on a range of amino acids provided as the sole nitrogen source. The aauAI mutant grows as wild type on inorganic nitrogen sources (e.g. nitrate, ammonium or urea), neutral amino acids (e.g. L-serine, L-alanine or L-valine), aromatic amino acids (e.g. L-phenylalanine, L-tryptophan or L-tyrosine) and basic amino acids such as L-arginine, L-ornithine, L-asparagine or L-glutamine, but grows poorly on the acidic amino acids, L-glutamate and L-aspartate. The heterozygous 


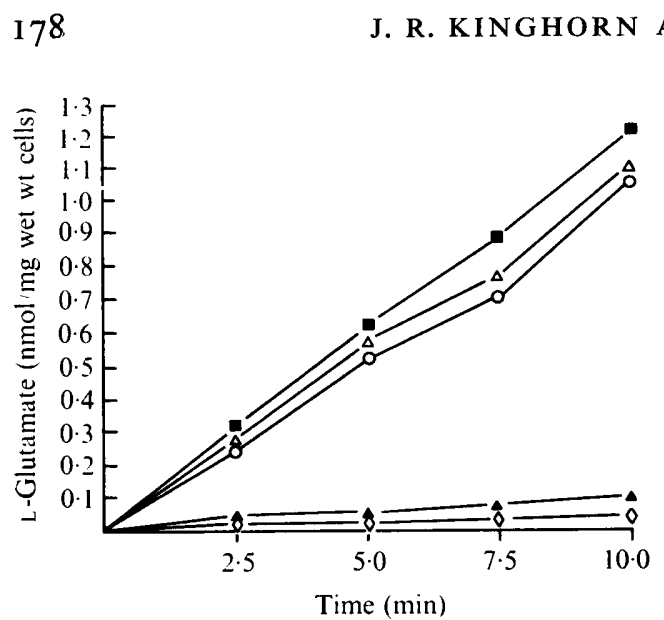

Fig. 3

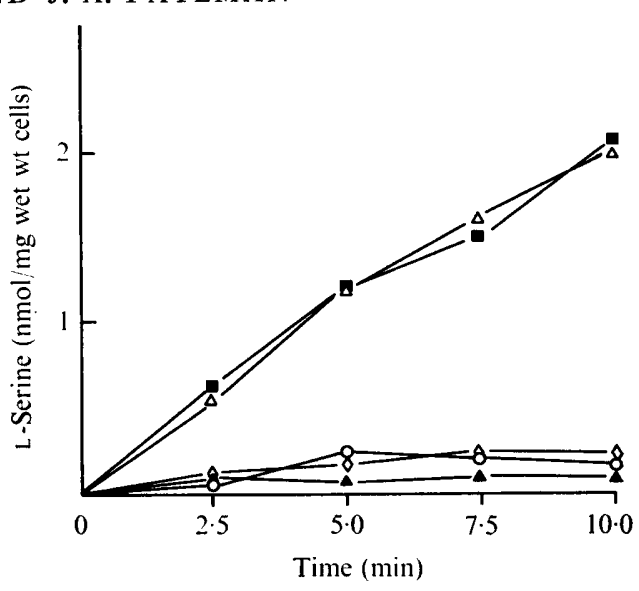

Fig. 4

Fig. 3. L-Glutamate transport by heterozygous diploids of wild-type and aau mutants. The cells were grown on $-\mathrm{N}$ medium $+\mathrm{I} 0 \mathrm{~mm}$-urea of $18 \mathrm{~h}$.

$$
\square, \frac{\text { Wild type }}{\text { wild type }} ; \quad \triangle, \frac{a a u A I}{a a u A^{+}} ; \quad \bigcirc, \frac{a a u B I}{a a u B^{+}} ; \diamond, \frac{a a u C I}{a a u C^{+}} ; \quad \Delta, \frac{a a u D I}{a a u D^{+}} \text {. }
$$

Fig. 4. Transport of $\mathrm{L}$-serine by wild-type and aau mutants. The cells were grown on $-\mathrm{N}$ medium +

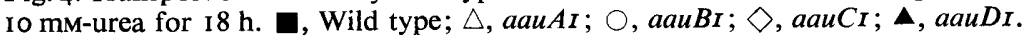

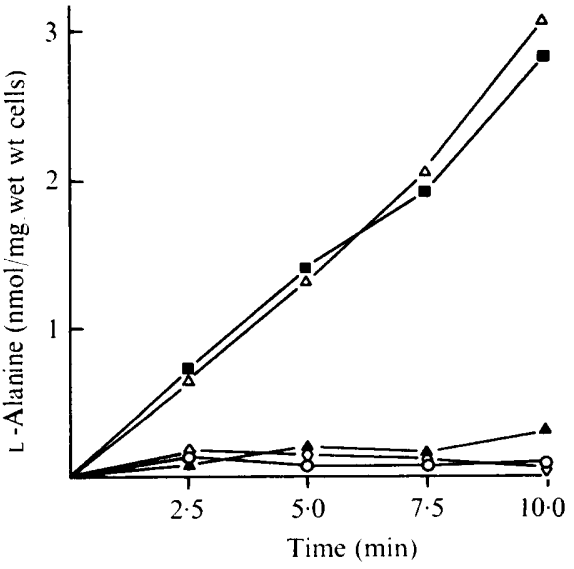

Fig. 5

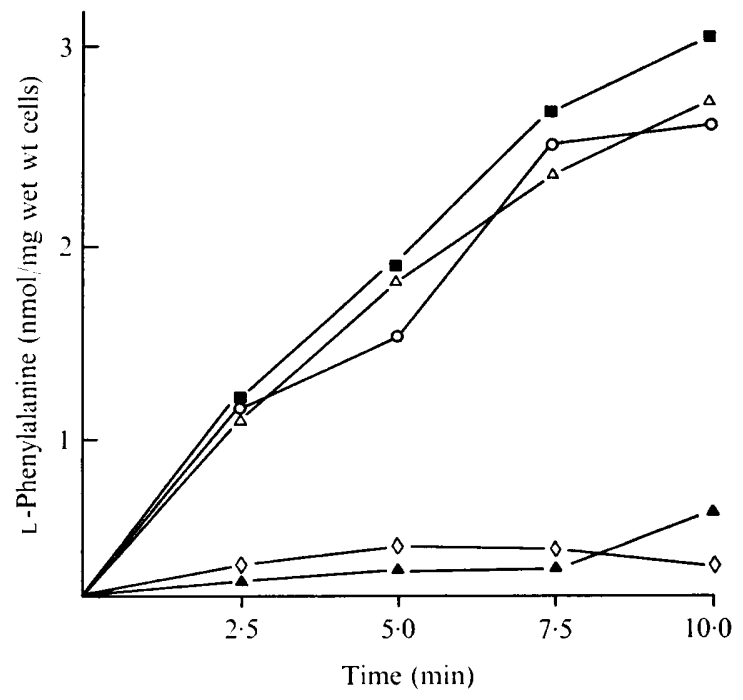

Fig. 6

Fig. 5. Transport of L-alanine by wild-type and aau mutants. The cells were grown on $-\mathrm{N}$ medium + Io mM-urea for $18 \mathrm{~h}$. W, Wild type; $\triangle, a a u A r ; O, a a u B I ; \diamond, a a u C I ; \Delta, a a u D I$.

Fig. 6. Transport of $\mathrm{L}$-phenylalanine by wild-type and aau mutants. The cells were grown on $-\mathrm{N}$ medium + $10 \mathrm{~mm}$-urea for $18 \mathrm{~h}$. W, Wild type; $\triangle$, aauAr; $\bigcirc$, aauBI; $\diamond$, aauCI; $\Delta$, aauDI. 
Table I. Growth responses of aau mutants on certain nitrogen sources

\begin{tabular}{|c|c|c|c|c|c|c|c|c|c|}
\hline Nitrogen source* & $\begin{array}{l}\text { Wild } \\
\text { type }\end{array}$ & $\operatorname{aauAI}$ & $\frac{\operatorname{aau} A I}{\operatorname{aau} A^{+}}$ & $a a u B I$ & $\frac{a a u B I}{a a u B^{+}}$ & $a a u C I$ & $\frac{a a u C I}{a a u C^{+}}$ & $a a u D I$ & $\frac{a a u D I}{a a u D^{+}}$ \\
\hline $\begin{array}{l}\text { Urea } \\
\text { Ammonium } \\
\text { Nitrate }\end{array}$ & $\begin{array}{l}++ \\
++ \\
++\end{array}$ & $\begin{array}{l}++ \\
++ \\
++\end{array}$ & $\begin{array}{l}++ \\
++ \\
++\end{array}$ & $\begin{array}{l}++ \\
++ \\
++\end{array}$ & $\begin{array}{l}++ \\
++ \\
++\end{array}$ & $\begin{array}{l}++ \\
++ \\
++\end{array}$ & $\begin{array}{l}++ \\
++ \\
++\end{array}$ & $\begin{array}{l}++ \\
++ \\
++\end{array}$ & $\begin{array}{l}++ \\
++ \\
++\end{array}$ \\
\hline $\begin{array}{l}\text { L-Aspartate } \\
\text { L-Glutamate }\end{array}$ & $\begin{array}{l}++ \\
++\end{array}$ & $\begin{array}{l}+ \\
+\end{array}$ & $\begin{array}{l}++ \\
++\end{array}$ & $\begin{array}{l}+ \\
+\end{array}$ & $\begin{array}{l}++ \\
++\end{array}$ & $\begin{array}{l}+ \\
+\end{array}$ & $\begin{array}{l}+ \\
+\end{array}$ & $\begin{array}{l}+ \\
+\end{array}$ & $\begin{array}{l}+ \\
+\end{array}$ \\
\hline $\begin{array}{l}\text { L-Alanine } \\
\text { L-Serine } \\
\text { L-Valine }\end{array}$ & $\begin{array}{l}++ \\
++ \\
++\end{array}$ & $\begin{array}{l}++ \\
++ \\
++\end{array}$ & $\begin{array}{l}++ \\
++ \\
++\end{array}$ & $\begin{array}{l}+ \\
+ \\
+\end{array}$ & $\begin{array}{l}++ \\
++ \\
++\end{array}$ & $\begin{array}{l}+ \\
+ \\
+\end{array}$ & $\begin{array}{l}+ \\
+ \\
+\end{array}$ & $\begin{array}{l}+ \\
+ \\
+\end{array}$ & $\begin{array}{l}+ \\
+ \\
+\end{array}$ \\
\hline $\begin{array}{l}\text { L-Phenylalanine } \\
\text { L-Tryptophan } \\
\text { L-Tyrosine }\end{array}$ & $\begin{array}{l}++ \\
++ \\
++\end{array}$ & $\begin{array}{l}++ \\
++ \\
++\end{array}$ & $\begin{array}{l}++ \\
++ \\
++\end{array}$ & $\begin{array}{l}++ \\
++ \\
++\end{array}$ & $\begin{array}{l}++ \\
++ \\
++\end{array}$ & $\begin{array}{l}+ \\
+ \\
+\end{array}$ & $\begin{array}{l}+ \\
+ \\
+\end{array}$ & $\begin{array}{l}+ \\
+ \\
+\end{array}$ & $\begin{array}{l}+ \\
+ \\
+\end{array}$ \\
\hline $\begin{array}{l}\text { L-Glutamine } \\
\text { L-Asparagine } \\
\text { L-Arginine } \\
\text { L-Ornithine }\end{array}$ & $\begin{array}{l}++ \\
++ \\
++ \\
++\end{array}$ & $\begin{array}{l}++ \\
++ \\
++ \\
++\end{array}$ & $\begin{array}{l}++ \\
++ \\
++ \\
++\end{array}$ & $\begin{array}{l}++ \\
++ \\
++ \\
++\end{array}$ & $\begin{array}{l}++ \\
++ \\
++ \\
++\end{array}$ & $\begin{array}{l}++ \\
++ \\
++ \\
++\end{array}$ & $\begin{array}{l}++ \\
++ \\
++ \\
++\end{array}$ & $\begin{array}{l}++ \\
++ \\
++ \\
++\end{array}$ & $\begin{array}{l}++ \\
++ \\
++ \\
++\end{array}$ \\
\hline
\end{tabular}

++ , Wild-type growth (this varies with the nitrogen source); + , about $50 \%$ of wild-type growth.

* Added at $10 \mathrm{~mm}$ final concentration to solid $-\mathrm{N}$ medium.

Table 2. Growth responses of aau mutants on certain carbon sources

\begin{tabular}{|c|c|c|c|c|c|c|c|c|c|}
\hline Carbon source* & $\begin{array}{l}\text { Wild } \\
\text { type }\end{array}$ & $\operatorname{aau} A \mathrm{I}$ & $\frac{\operatorname{aauAI}}{\operatorname{aauA} A^{+}}$ & $a a u B I$ & $\frac{a a u B I}{a a u B^{+}}$ & $a a u C I$ & $\frac{a a u C I}{a a n C^{+}}$ & $a a u D I$ & $\frac{a a u D I}{a a u D^{+}}$ \\
\hline $\begin{array}{l}\text { Galactose I \% } \\
\text { Maltose I \% } \\
\text { Sedoheptulose I \% } \\
\text { Acetate I \% } \\
\text { Glycerol I \% }\end{array}$ & $\begin{array}{l}++ \\
++ \\
++ \\
++ \\
++\end{array}$ & $\begin{array}{l}++ \\
++ \\
++ \\
++ \\
++\end{array}$ & $\begin{array}{l}++ \\
++ \\
++ \\
++ \\
++\end{array}$ & $\begin{array}{l}++ \\
++ \\
++ \\
++ \\
++\end{array}$ & $\begin{array}{l}++ \\
++ \\
++ \\
++ \\
++\end{array}$ & $\begin{array}{l}++ \\
++ \\
++ \\
++ \\
++\end{array}$ & $\begin{array}{l}++ \\
++ \\
++ \\
++ \\
++\end{array}$ & $\begin{array}{l}++ \\
++ \\
++ \\
++ \\
++\end{array}$ & $\begin{array}{l}++ \\
++ \\
++ \\
++ \\
++\end{array}$ \\
\hline $\begin{array}{l}\text { L-Glutamate } 100 \mathrm{mM} \\
\text { L-Aspartate } 100 \mathrm{mM} \\
\text { L-Alanine } 100 \mathrm{mM}\end{array}$ & $\begin{array}{l}++ \\
++ \\
++\end{array}$ & $\begin{array}{c}- \\
- \\
++\end{array}$ & $\begin{array}{l}++ \\
++ \\
++\end{array}$ & $\begin{array}{l}- \\
- \\
-\end{array}$ & $\begin{array}{l}++ \\
++ \\
++\end{array}$ & $\begin{array}{l}- \\
- \\
-\end{array}$ & $\begin{array}{l}- \\
- \\
-\end{array}$ & $\begin{array}{l}- \\
- \\
-\end{array}$ & $\begin{array}{l}- \\
- \\
-\end{array}$ \\
\hline
\end{tabular}

++ , Wild-type growth (this varies with the carbon source); - , poor growth.

* Basal medium $=$ solid $-\mathrm{N}$ medium + Io mM-ammonium.

diploid aauAr/aauA $A^{+}$grows as wild type on L-glutamate and L-aspartate, indicating that the $a a u A I$ mutation is recessive. Mutation in the $a a u B$ gene results in poor growth on acidic and neutral amino acids and is recessive for growth characteristics. The $a a u C I$ and aauDI mutants are rather similar to each other in that they both grow poorly on acidic, neutral and aromatic, but as wild type on basic amino acids. They are dominant in the heterozygous diploid.

All classes of mutants appear to have wild-type growth on certain carbon sources tested (Table 2). However, the utilization of L-glutamate, L-aspartate and L-alanine as sole carbon sources by the mutants was relatively poorer than their utilization of these amino acids as sole nitrogen sources. This is not surprising since larger quantities of the amino acid would be necessary to provide a sufficient energy source. The mutants aauAI and aauBI appear recessive for growth on L-glutamate as a carbon and nitrogen source, while aauCr and aauDI are dominant (Fig. 7). 


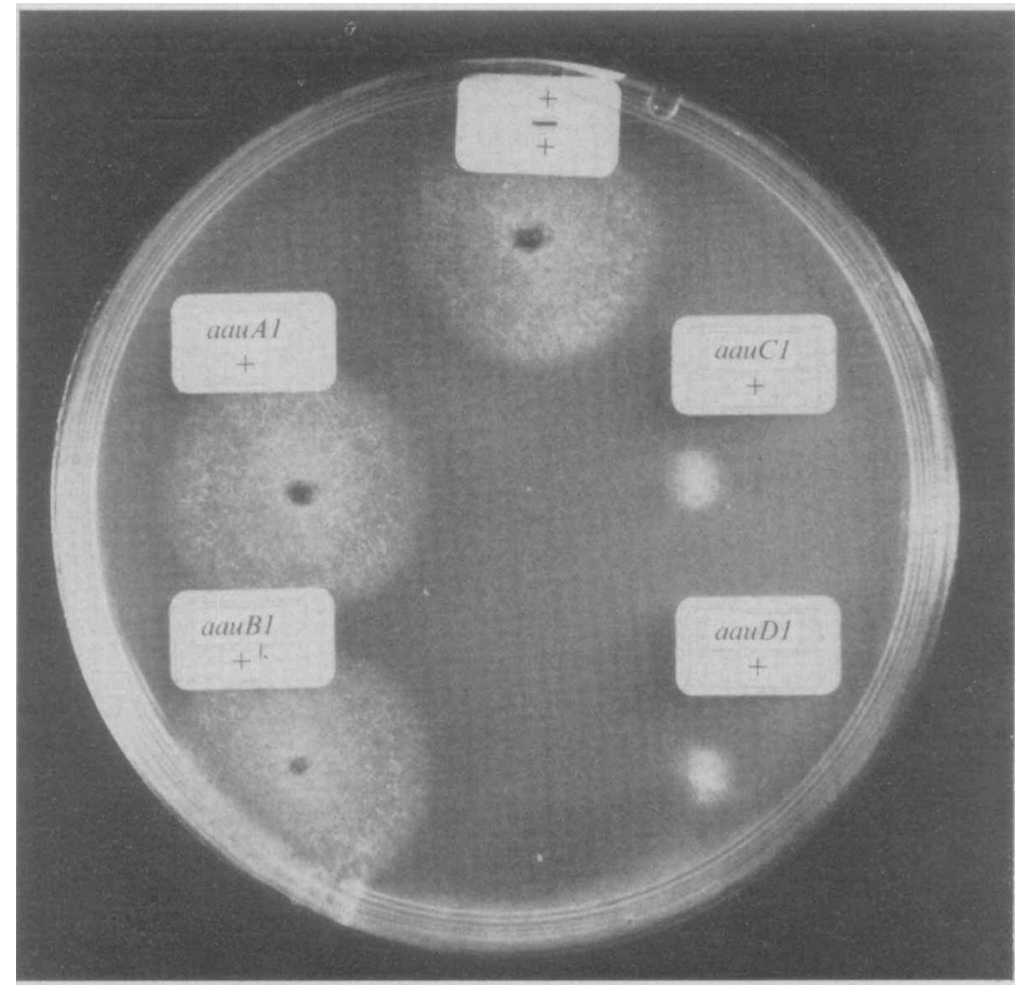

Fig. 7. Growth of a homozygous wild-type diploid and diploids heterozygous for aau mutants with L-glutamate as sole carbon and nitrogen source. - $\mathrm{CN}$ medium (solid) plus $100 \mathrm{mM}$-L-glutamate for $48 \mathrm{~h}$. + , Wild-type allele.

\section{Resistance of aau mutants to certain toxic analogues of amino acids and inorganic nitrogen}

An attempt was made to correlate the transport deficiencies of the various aau mutants with resistance to certain toxic analogues. A number of amino acid analogues reported to be inhibitory to bacteria and yeast did not inhibit wild-type $A$. nidulans. These included analogues of L-glutamate (D-glutamate), L-aspartate (D-aspartate), L-arginine (canavanine), L-proline (azetidine-2-carboxylic acid), L-lysine (thiosine), L-methionine (ethionine) and glutamine (glutamyl-hydrazine). However, three analogues were found to inhibit the growth of $A$. nidulans: aspartate hydroxamate, glutamate hydroxamate and D-serine. Auxanographic tests of a wild-type strain showed that the inhibitions of growth by the three analogues were reversed by L-asparagine, L-glutamine and L-serine, respectively. In addition, the aau mutants were tested for resistance to $p$-fluorophenylalanine, 3-amino tyrosine $\mathrm{HCl}$ (Sinha, I969), methylammonium (Arst \& Cove, 1969) and thiourea (Dunn \& Pateman, 1972), which are toxic analogues of L-phenylalanine, L-tyrosine, ammonium and urea, respectively. The mutants meaA8, uruAI, SER-9, fpaD43, ahyAI and ghyAI, each known to be resistant to at least one of the analogues, were tested as controls and to determine if aau mutants shared any resistance characteristics with various known resistant mutants (Table 3). aauAI is sensitive to all seven toxic analogues; $a a u B I$ is resistant to D-serine only; $a a u C r$ and $a a u D I$ are resistant to $p$-fluorophenylalanine, $\mathrm{D}$-serine and 3 -amino tyrosine. $a a u B I$ is recessive, while $a a u C I$ and $a a u D I$ are dominant for resistance. uruAI, meaA8, SER-9, ahyAI and 
Amino acid transport in $A$. nidulans

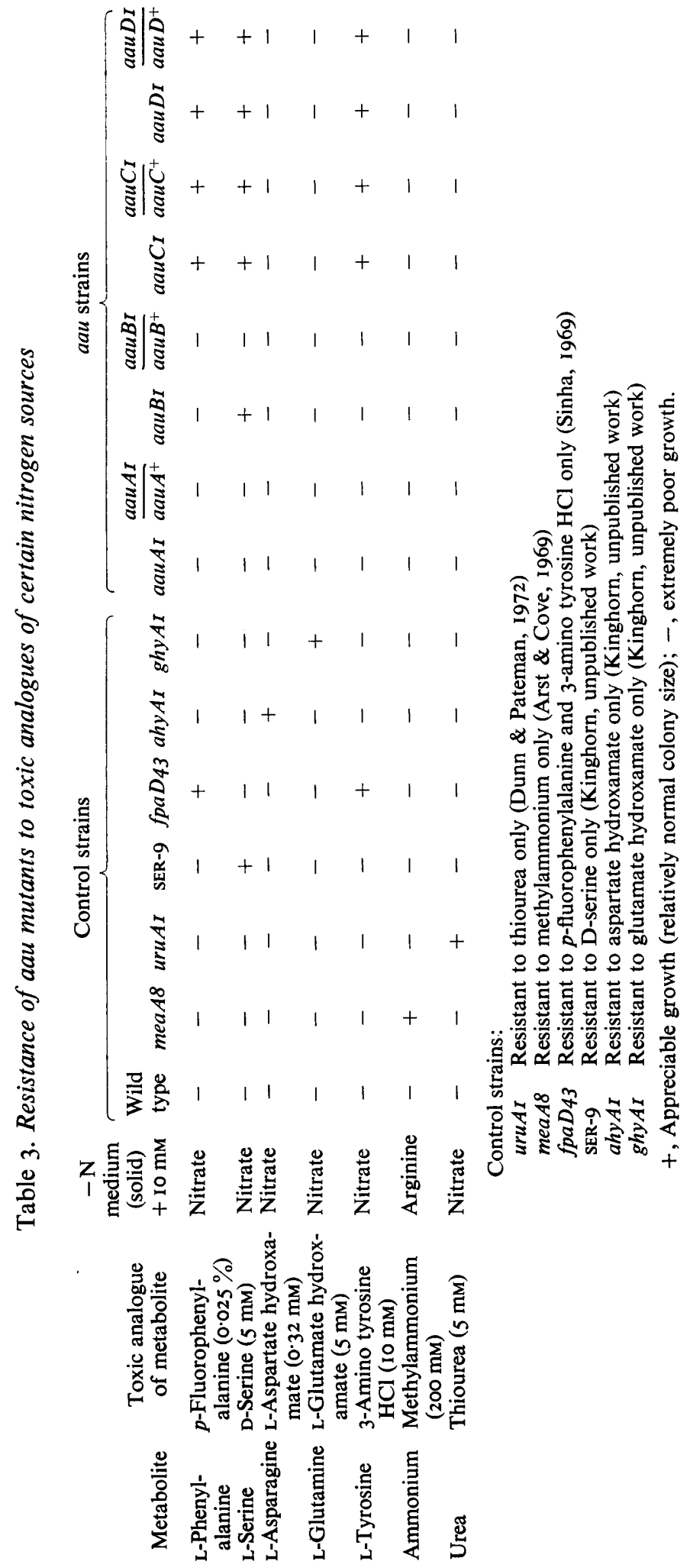


aauA mutants have no common resistance characteristics. fpaD 43 shares some resistance characteristics with $a a u C I$ and $a a u D I$, i.e. dominance and resistance to $p$-fluorophenylalanine and 3-amino tyrosine (Sinha, 1969). However, fpaD43 differs in that it is not resistant to D-serine.

\section{DISCUSSION}

It is clear that mutation in at least four loci, $a a u A, a a u B$, aauC and aau $D$, in $A$. nidulans results in impaired transport of certain amino acids. These are in addition to $f p a D$ described by Sinha (1969). There are three main lines of evidence to support this: the transport levels of amino acids in the mutants; the phenotypes of the mutants on certain nitrogen or carbon sources; and their cross-resistance patterns to toxic analogues of certain nitrogen metabolites. Moreover, since the growth rates of the aau mutants are similar to that of the wild type when grown on minimal medium, it is concluded that the physiological defect is limited to the transport function.

The existence of $a a u A I$, in which only L-glutamate and L-aspartate transport is impaired, suggests the presence of a specific system or component for L-glutamate and L-aspartate transport rather similar to that in $N$. crassa (Pall, 1969) and $P$. chrysogenum (Hunter \& Segel, 197I).

Mutation in the $a a u B$ gene reduces the uptake of acidic and neutral amino acids and is rather similar to the nap and un- $t$ mutations in $N$. crassa. Several explanations can be advanced to explain such mutations. The most likely is that $a a u B I$ results in an altered functional component (e.g. an energy-generating system) which is shared by both the acidic and neutral amino-acid transport systems. The fact that the $a a u B I$ mutation is recessive tends to support this.

Mutation at the $a a u C$ and $a a u D$ loci results in altered transport levels of acidic, neutral and aromatic amino acids. In contrast to $a a u A I$ and $a a u B I$, but similar to $f p a D_{43}$, both $a a u C I$ and $a a u D_{I}$ are dominant in the heterozygous diploid.

Sinha (1969) discussed the possibility that $f p a D$ plays a regulatory role in amino acid transport. However, the isolation of similar dominant mutations at another two loci rather discounts this hypothesis. It seems unlikely that all three loci are involved in regulation. An alternative explanation is that the loci code for structural proteins which are intimately associated with and shared by the acidic, neutral and aromatic amino acid transport systems. The proteins determined by these three loci (and perhaps others presently unknown) are essential for normal amino acid transport function. An extension of this hypothesis provides a plausible explanation for the dominance or semi-dominance of these mutations. The heterozygous diploid contains normal and mutant alleles which specify both normal and abnormal transport proteins. An actual transport site might contain all normal, all abnormal, or some combination of molecules of the transport protein. If all transport sites contained sufficient abnormal components to reduce transport, the mutation would appear dominant.

The support received from the Science Research Council (grant No. B/RG/48502) is gratefully acknowledged. We thank Mr James Heggie for excellent photographic assistance. 


\section{REFERENCES}

Adelberg, E. A., MANdel, M. \& Chen, G. C. C. (1965). Optimal conditions for mutagenesis by $N$-methyl$N^{\prime}$-nitro- $N$-nitrosoguanidine in Escherichia coli K12. Biochemical and Biophysical Research Communications 18, 788-795.

ARsT, H. N. \& CovE, D. J. (1969). Methylammonium resistance in Aspergillus nidulans. Journal of Bacterio$\log y$ 98, $\mathrm{I} 284-1293$.

Benko, P. V., WoOd, T. C. \& Segel, I. H. (1967). Specificity and regulation of methionine transport in filamentous fungi. Archives of Biochemistry and Biophysics 122, 783-804.

Benko, P. V., Wood, T. C. \& Segel, I. H. (1969). Multiplicity and regulation of amino acid transport in Penicillium chrysogenum. Archives of Biochemistry and Biophysics 129, 498-508.

Clutterbuck, A. J. (1974). Aspergillus nidulans genetics. In Handbook of Genetics, vol. I. Edited by R. C. King. New York: Plenum Press.

Cove, D. J. (1966). The induction and repression of nitrate reductase in the fungus Aspergillus nidulans. Biochimica et biophysica acta $113,5 \mathrm{I}-56$.

Crabeel, M. \& Grenson, M. (1970). Regulation of histidine uptake by specific feedback inhibition of two histidine permeases in Saccharomyces cerevisiae. European Journal of Biochemistry 14, 197-204.

Dunn, E. \& Pateman, J. A. (1972). Urea and thiourea uptake in Aspergillus nidulans. Heredity 29, 129.

Girs, J. J. \& Grenson, M. (1967). Multiplicity of the amino acid permeases in Saccharomyces cerevisiae. III. Evidence for a specific methionine-transporting system. Biochimica et biophysica acta 135, 507-5I6.

Grenson, M. (1966). Multiplicity of the amino acid permeases in Saccharomyces cerevisiae. II. Evidence for a specific lysine-transporting system. Biochimica et biophysica acta 127, 339-346.

Grenson, M. \& Hennaut, C. (197I). Mutation affecting activity of several distinct amino acid transport systems in Saccharomyces cerevisiae. Journal of Bacteriology 105, 477-482.

Grenson, M. \& Hou, C. (1972). Ammonia inhibition of the general amino acid permease and its suppression in NADPH-specific glutamate dehydrogenase mutants of Saccharomyces cerevisiae. Biochemical and Biophysical Research Communications 48, 749-756.

Grenson, M., Hou, C. \& Crabeel, M. (1970). Multiplicity of the amino acid permeases in Saccharomyces cerevisiae. IV. Evidence for a general amino acid permease. Journal of Bacteriology 103, 770-777.

Grenson, M., Mousset, M., Wiame, J. M. \& BéCHet, J. (I966). Multiplicity of the amino acid permeases in Saccharomyces cerevisiae. I. Evidence for a specific arginine transporting system. Biochimica et biophysica acta $127,325-338$.

Gupta, R. K. \& Pramer, D. (1970). Amino acid transport by the filamentous fungi Arthrobotrys conoides. Journal of Bacteriology 103, 120-1 30.

Hackette, S. L., Skye, G. E., Burton, C. \& Segel, I. H. (1970). Characterization of an ammonium transport system in filamentous fungi with methylammonium $-{ }^{14} \mathrm{C}$ as the substrate. Journal of Biological Chemistry 245, 4241-4250.

Herman, C. \& Clutterbuck, A. J. (1966). A method for selection of auxotrophs by means of 'spidery' growth. Aspergillus Newsletter 7, 13-14.

Hunter, D. R. \& Segel, I. H. (I97I). Acidic and basic amino acid transport systems of Penicillium chrysogenum. Archives of Biochemistry and Biophysics 144, 168-183.

JACOBSON, E. S. \& METZENBERG, R. L. (1968). A new gene which affects uptake of neutral and acidic amino acids in Neurospora crassa. Biochimica et biophysica acta 156, 140-147.

JoNES, O. T. G. (1963). The accumulation of amino-acids by fungi, with particular reference to the plant parasitic fungus Botrytis fabae. Journal of Experimental Botany 14, 399-4I I.

KAPPY, M.S. \& MetZenBerg, R. L. (1965). Studies on the basis of ethionine-resistance in Neurospora. Biochimica et biophysica acta 107, 425-433.

Kinghorn, J. R. \& Pateman, J. A. (1972). Regulation of glutamate transport in Aspergillus nidulans. Heredity 29, 128.

Kinghorn, J. R. \& Pateman, J. A. (1973). NAD and NADP L-glutamate dehydrogenase activity and ammonium regulation in Aspergillus nidulans. Journal of General Microbiology 78, 39-46.

Kinghorn, J. R. \& Pateman, J. A. (1974a). The effect of the carbon source on ammonium regulation in Aspergillus nidulans. Molecular and General Genetics 128, 95-98.

Kinghorn, J. R. \& Pateman, J. A. (I974b). The regulation of NAD L-glutamate dehydrogenase in Aspergillus nidulans. Genetical Research 23, $119-124$.

LESTER, G. (1966). Genetic control of amino acid permeability in Neurospora crassa. Journal of Bacteriology 9I, $677-684$. 
McCully, K. S. \& Forbes, E. (1965). The use of $p$-fluorophenylalanine with 'master strains' of Aspergillus nidulans for assigning genes to linkage groups. Genetical Research 6, 352-359.

PALl, M. L. (1969). Amino acid transport in Neurospora crassa. I. Properties of two amino acid transport systems. Biochimica et biophysica acta 173, I I3-1 27.

Pateman, J. A., Dunn, E., Kinghorn, J. R. \& Forbes, E. (1974). Ammonium and methylammonium transport in wild type and mutant cells of Aspergillus nidulans. Molecular and General Genetics 133, 225-236.

Pateman, J. A., Kinghorn, J. R., Dunn, E. \& Forbes, E. (1973). Ammonium regulation in Aspergillus nidulans. Journal of Bacteriology 114, 943-950.

Pontecorvo, G., Roper, J. A., Hemmons, L. M., Macdonald, K. D. \& Bufton, A. W. J. (1953). The genetics of Aspergillus nidulans. Advances in Genetics 5, I4I-238.

SinHA, U. (1969). Genetic control of the uptake of amino acids in Aspergillus nidulans. Genetics 62, 495-505.

SKYe, G. E. \& Segel, I. H. (1970). Independent regulation of cysteine and cystine transport in Penicillium chrysogenum. Archives of Biochemistry and Biophysics 138, 306-3 I8.

STADLER, D. (1966). Genetic control of the uptake of amino acids in Neurospora. Genetics 54, 677-685.

Surdin, Y., Sly, W., Sire, J., Bordes, A. M. \& de Robichon-Szulmajster, H. (1965). Propriétés et contrôle génétique du système d'accumulation des acides aminés chez Saccharomyces cerevisiae. Biochimica et biophysica acta 107, 546-566. 